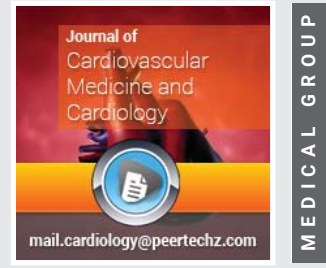

\title{
The Impact of Low Carb- KETO Diets on CAD-Why more Research is needed
}

\section{Richard M Fleming* and Matthew R Fleming, BS, NRP}

PhD, MD, JD, FHHI-OI-Camelot, Los Angeles, CA, USA
Received: 23 April, 2020

Accepted: 11 May, 2020

Published: 12 May, 2020

*Corresponding author: Richard M Fleming, PhD, MD, JD, FHHI-OI-Camelot, Los Angeles, CA, USA, E-mail:rmfmd7@yahoo.com

ORCID: https://orcid.org/0000-0001-9964-1518 Keywords: FMTVDM; Low Carb-Ketogenic Diets (LCKD); Heart disease; Coronary artery disease

https://www.peertechz.com

Check for updates

\begin{abstract}
Coronary Artery Disease (CAD) is the result of multiple factors - many of which are now routinely tested for - which interact with each other and the patient to produce an inflammatory effect within the walls of the coronary arteries, impairing the ability of these arteries to increase coronary blood flow when needed. Fundamental to changes in these multiple factors as measured by blood tests, are the effect various diets have when consumed by people for an extended period of time. However, changes in these blood tests are poorly correlated with changes in CAD - limiting our current knowledge about the true effect these diets have on CAD. This paper takes a look at the only studies, which have looked at the impact of LowCarb-Ketogenic diets (LCKD) on these blood tests and corresponding changes in CAD.
\end{abstract}

\section{Introduction}

It is well recognized that coronary artery disease and cancer are the result of inflammatory changes, which occur within the tissues of the body - specifically the walls of the coronary arteries (CAD) and within the specific organ (e.g. breast, colon) tissue in question [1-3]-and not the blood (Figure 1). Despite this obvious difference between blood and tissue, medical studies looking at the impact of diets and drugs have primarily utilized changes in qualitative or at best semi-quantitative imaging [4-8], weight and blood tests to monitor presumed changes in heart disease and cancer.

However, changes in heart disease and cancer cannot be measured through the mere use of blood tests alone, since these blood tests merely tell us what is happening within the blood and not what is happening in the tissues of the body proper [9-11]-hence, the persistent debate about the consequences of different diets or drugs, and the potential risk for CAD and cancer [12-17]-and the persistent doubt and confusion by the public and media [18-21]. This review looks at the information, which exists in the few studies that have actually compared changes in CAD with changes in weight and blood tests, which measure markers of CAD inflammation.

The only published studies, which have looked at low carbohydrate ketogenic diets (LCKG)-discussed in this paper -have shown variable changes in weight loss and blood tests, while simultaneously showing progression of $\mathrm{CAD}$ at the tissue level when semi-quantitatively measured.

\section{Foundational work}

The original work leading up to the investigation of LCKD began in the early to mid-1990s [22] and was associated with the development of the Inflammation and Heart Disease Theory [1]. The initial focus was the impact of dietary and drug treatment on total cholesterol and triglyceride levels. A total of 70-subjects were divided into four treatment groups including a control group (Group 1) who received neither dietary counseling nor medications to reduce lipid levels. A second group (Group 2) received 18-months of dietary counseling encouraging them to follow a vegetarian diet. Alternatively, they were provided with dietary instructions on AHA step I and II. A third group (Group 3) received dietary counseling for their first 6-months of the study with lipid lowering medications for the duration of 18-months -thus providing information on what happens when patients no longer receive dietary counseling. The final group (Group 4) were followed initially for 18-months without any intervention and then were placed on lipid lowering medications for 18-months.

While the study is not very sophisticated by today's standards, it demonstrated the importance of continued dietary counseling. As shown in Figures 2 and 3, continued dietary 


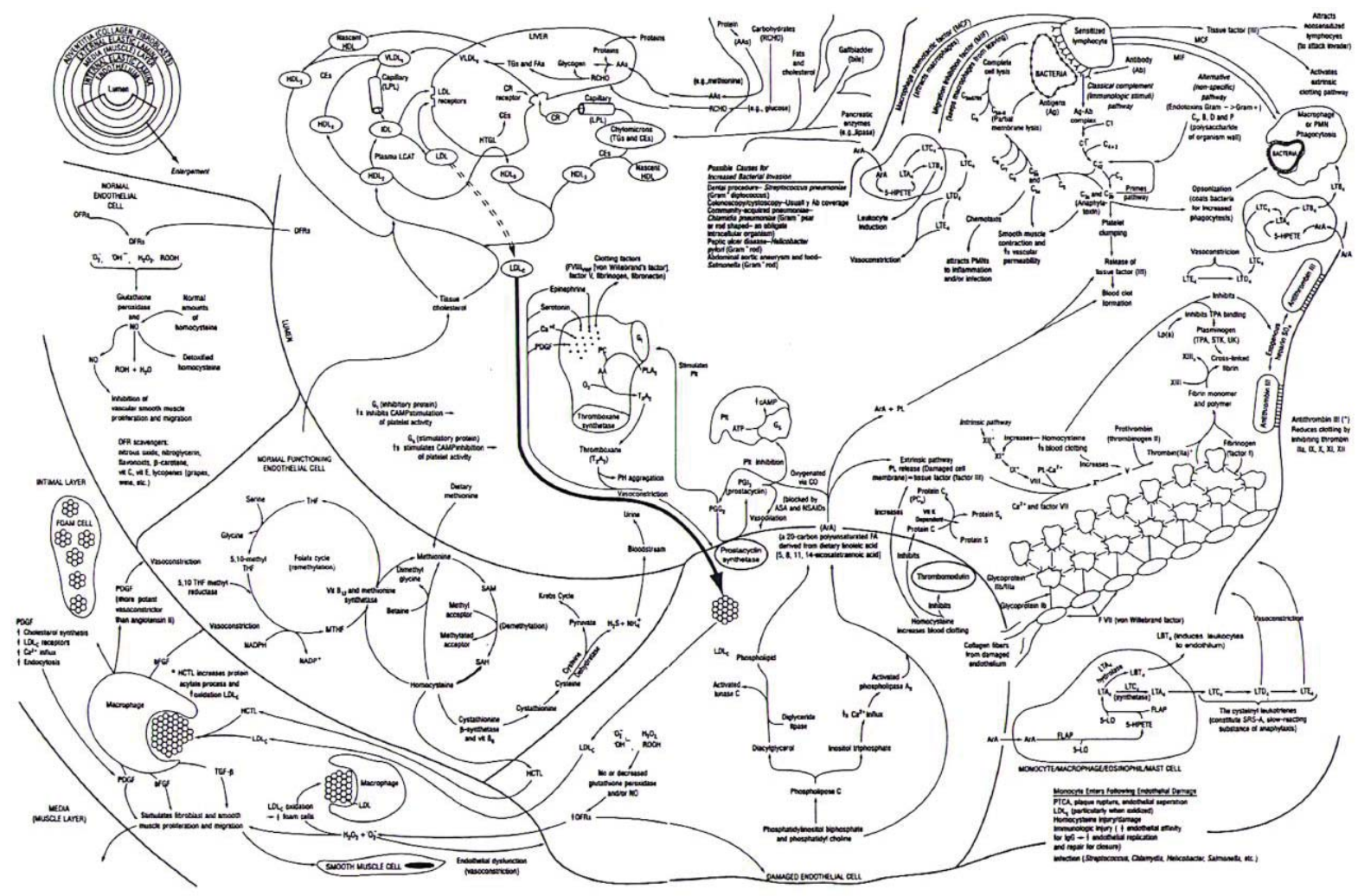

Figure 1: The Fleming Unified Theory of Vascular - Coronary Artery Disease. [1].

The various factors involved in the process of coronary artery disease inflammation are schematically shown as they interact with each other and the walls of the coronary arteries. The resulting inflammatory process initially impairs the ability of the coronary arteries to dilate upon demand to increase coronary blood flow and later will encroach upon the coronary lumen making it visible by coronary arteriography $[1,4,5]$.

counseling (Group 2) had the greatest impact on lowering total cholesterol levels, while Group 3, which received lipid lowering medications and at least 6 -months of dietary counseling had the greatest impact on lowering triglyceride levels. Doing nothing (Group 1) or using medications alone (Group 4), showed either worsening of lipid levels or a blunted response compared to those who received dietary counseling. Thus this study demonstrated the absolute necessity of modifying diet to obtain maximum benefit from medications used for lipid reduction.

This foundational work not only demonstrated the importance of dietary counseling but the importance of providing sufficient time for that counseling and by someone with experience in nutrition. Thus establishing the foundation for the studies, which followed thereafter.

\section{Coronary artery disease is aggressive and is caused by more than just cholesterol}

As mentioned previously, during this period of investigation into the role dietary counseling plays in the successful treatment of CAD, the first author developed the theory of Inflammation and Heart (Vascular) Disease [1]. The understanding of these multiple factors producing CAD inflammation discussed on 20/20 and in Stop Inflammation Now! [23]-and the aggressiveness of inflammatory CAD was demonstrated through Positron Emission Tomography studies.
The first publication demonstrated the aggressiveness with which CAD could progress [24], when a 41-year old father showed progression from mild to severe CAD within 104-days of changing his dietary habits - signaling for the first time the potentially life threatening changes to coronary blood flow, which can occur from dietary change alone.

The second paper investigated the effect of a vegetarian diet with stress reduction on both myocardial blood flow and myocardial viability - the first such study to do so [25]. In this study 31-participants were followed for 1-year after being placed on a vegetarian diet with stress reduction and lifestyle management. The studyused $13 \mathrm{~N}-\mathrm{Ammonia}(\mathrm{NH})$ for myocardial perfusion imaging (MPI) and 18F-Flurodeoxyglucose (FDG) for viability. Of the 224 segments (7-segments per patient per study) studied, $25.9 \%$ showed improvement, $49.6 \%$ stabilized without significant change and $26.3 \%$ showed progression of disease - despite improvements in lipid levels-demonstrating that more than lipid levels were involved in the process of developing inflammatory coronary artery disease.

These two papers provided confirmation of the Inflammation and Heart Disease Theory first discussed at American Heart Association meetings in the mid to late 1990 s and published in 1999 [1] and the need to investigate the multi factorial components of Inflammation and Heart Disease (Figure 1) in any further studies investigating either the effect of diets, drugs or their combined effect upon heart disease. 


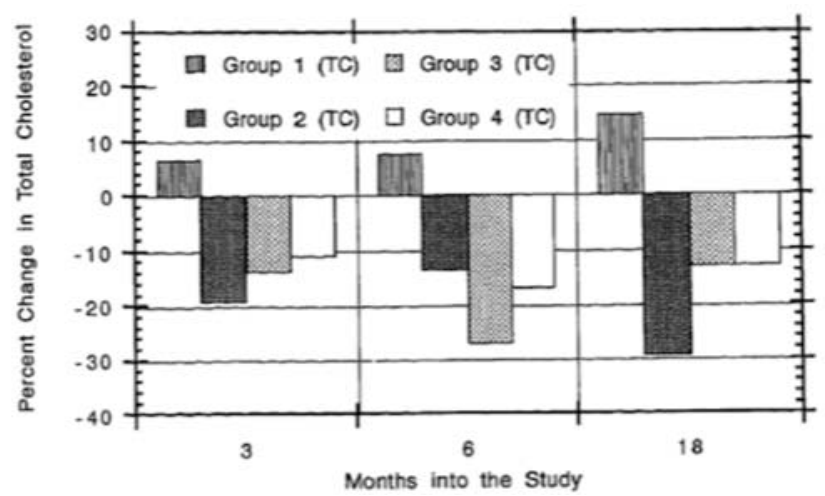

Figure 2: Changes in total cholesterol levels over 18-months.

Changes in total cholesterol levels as measured by those who received no treatment (Group 1), those who receive dietary counseling only (Group 2), those who received dietary counseling for 6-months and lipid lowering medications for 18-months (Group 3) and those who received lipid lowering medications without dietary counseling (Group 4).

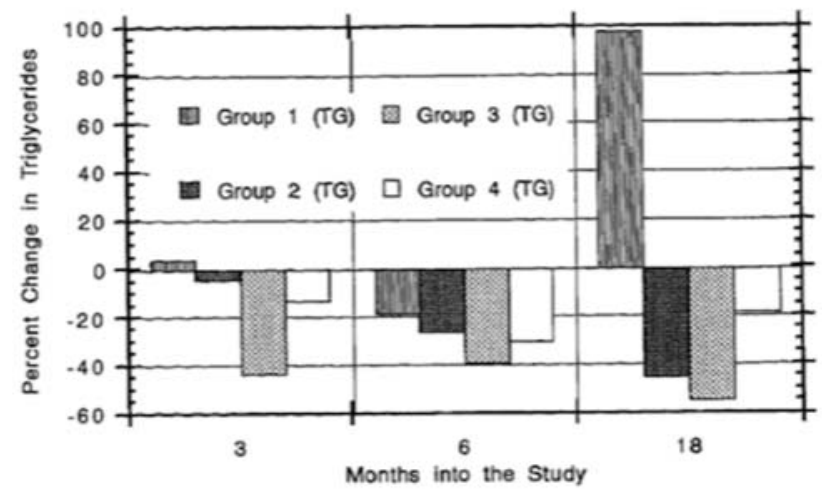

Figure 3: Changes in triglyceride levels over 18-months.

Changes in triglyceride levels as measured by those who received no treatment (Group 1), those who receive dietary counseling only (Group 2), those who received dietary counseling for 6-months and lipid lowering medications for 18-months (Group 3) and those who received lipid lowering medications without dietary counseling (Group 4).

\section{Investigating dietary impact on a multi factorial theory of inflammation and heart disease}

With an enhanced understanding of the inflammatory causes of CAD and what needed to be measured, the next study began measuring not only cholesterol and triglyceride levels, but also, fibrinogen, homocysteine, lipoprotein(a), c-reactive protein, the potential influence of certain bacterial pathogens [26] and coronary blood flow itself-using the then available semi-quantitative method of percent of area (extent) and percent reduction from maximal blood flow shown during the cardiac imaging (severity).

\section{The first of the LCKD studies [27]}

At this point the first author had no plans to investigate LCKD of any kind. The premise that eliminating the fundamental fuel used by the body for the alternative back up fuel had no rationale for expecting this approach to be beneficial to the coronary arteries. Instead he focused on the information at hand-which had itself, only shown improvement in CAD in a quarter of the arterial segments investigated [25].
In 26-individuals, both a MPI using single photon emission computed tomography (SPECT) imaging and an echocardiogram were obtained at the beginning and end of a 1-year period of time. The dietary counseling instructed each individual to consume approximately $10-\mathrm{kcal} /$ pound body weight/day. The goal was not to obtain weight loss but to maintain weight while determining the effect of a diet, which was $70 \%$ complex carbohydrates, $15 \%$ protein and $15 \%$ fat with a ratio of 2:1 polyunsaturated and monosaturated, to saturated fats. In addition to the dietary instructions, participants also received medical management as detailed in the paper.

Blood tests were obtained every 6-weeks looking at total cholesterol, LDL cholesterol, HDL cholesterol, triglyceride, fibrinogen, homocysteine, lipoprotein(a), and C-reactive protein. Our expectation-based upon our prior dietary counseling experience [22]-was that participants were following the recommended changes in dietary intake. However, once the SPECT imaging and echocardiograms had been completed for all participants in the study and the results were analyzed-it was clear there were two completely different sets of outcomes for a group of people who were supposedly all following the same dietary regimen.

One group of people showed improvement in their coronary blood flow with recovery of viable myocardium in $43.75 \%$ of their heart segments studied. The other group showed a 5-10\% progression of CAD and deterioration in their coronary blood flow with no recovery of viable myocardium.

After thorough conversations with each study participant, it was discovered that those who showed improvements in their CAD had followed the prescribed dietary regimen (Treatment Group-TG), while those who experienced deterioration in coronary blood flow had all followed a High-protein (HPG) LCKD. This, as it turned out, would be the first study, which actually measured the impact of LCKD.

As shown in Table 1, the LCKD group showed increased levels in their measured blood tests, while the first group showed improvements-and even though the differences in these blood tests were not statistically significant-what was statistically significant was the change in coronary blood flow $(\mathrm{p}<0.001)$ shown in Table 2.

Not only was this the first study on the effect of LCKD, but it also demonstrated that the use of indirect blood-tests-markers for assessing the inflammatory process occurring within the walls of the coronary arteries, is inadequate and missed the treatment effect of dietary changes and if it misses the effect of dietary change, it most probably misses the treatment effect of drugs and interventional procedures as well.

\section{The second of the LCKD studies}

Following the continued measurements and discordant outcomes between serum blood tests routinely used to monitor treatment of CAD risk factors-including markers of lipids and inflammation-the next study was divided into two parts. The first part was to compare the outcomes of four fundamentally different diets, while the second part combined the results 
Table 1: Measured changes in blood tests from baseline. The treatment group representing those who followed the recommended dietary regimen and the high-protein group representing those following a LCKD.

Independent Variable Changes by Group

\begin{tabular}{|c|c|c|c|c|c|c|}
\hline Independent Variable & $\begin{array}{l}\text { Treatment } \\
\text { Group } \\
\text { Initial Values }\end{array}$ & $\begin{array}{l}\text { Treatment } \\
\text { Group } \\
\text { Final Values }\end{array}$ & $\begin{array}{c}\text { Percent Change } \\
\text { in Treatment } \\
\text { Group }\end{array}$ & $\begin{array}{l}\text { High-Protein } \\
\text { Group } \\
\text { Initial Values }\end{array}$ & $\begin{array}{l}\text { High-Protein } \\
\text { Group } \\
\text { Final Values }\end{array}$ & $\begin{array}{l}\text { Percent Change } \\
\text { in High-Protein } \\
\text { Group }\end{array}$ \\
\hline Weight & 178.7 & 182.7 & +2.2 & 194.7 & 194.3 & -0.2 \\
\hline Homocysteine & 8.9 & 8.7 & -2.8 & 6.9 & 9.0 & +3.0 \\
\hline Lipoprotein (a) & 47.5 & 57.6 & +21.2 & 5.0 & 10.5 & +110.0 \\
\hline C-reactive protein & 0.9 & 0.4 & -52.1 & 3.0 & 1.2 & +61.0 \\
\hline Triglycerides & 215.2 & 246.7 & -38.8 & 108.5 & 169.3 & +56.0 \\
\hline Total cholesterol & 222.6 & 188.6 & -15.3 & 132.5 & 156.7 & +18.2 \\
\hline HDL cholesterol & 50.6 & 46.5 & -8.0 & 50.0 & 45.7 & -9.6 \\
\hline LDL cholesterol & 132.8 & 117.3 & -11.7 & 60.5 & 77.3 & +27.8 \\
\hline VLDL cholesterol & 39.2 & 24.8 & -36.8 & 21.5 & 33.7 & +56.6 \\
\hline Fibrinogen & 371.1 & 347.9 & -6.2 & 292.0 & 329.5 & +12.8 \\
\hline
\end{tabular}

Table 2: Semi-quantitative changes in coronary blood flow as measured using Single Photon Emission Computed Tomography (SPECT) Imaging.

Changes in Extent and Severity of Disease

\begin{tabular}{|c|c|c|c|c|c|c|c|c|c|c|}
\hline & $\begin{array}{l}\text { Percent } \\
\text { Extent } \\
\text { LAD }\end{array}$ & $\begin{array}{l}\text { Percent } \\
\text { Severity } \\
\text { LAD }\end{array}$ & $\begin{array}{l}\text { Percent } \\
\text { Extent } \\
\text { RCA }\end{array}$ & $\begin{array}{c}\text { Percent } \\
\text { Severity } \\
\text { RCA }\end{array}$ & $\begin{array}{c}\text { Percent } \\
\text { Extent } \\
\text { LCx }\end{array}$ & $\begin{array}{l}\text { Percent } \\
\text { Severity } \\
\text { LCx }\end{array}$ & $\begin{array}{c}\text { Percent } \\
\text { Extent } \\
\text { L-C }\end{array}$ & $\begin{array}{l}\text { Percent } \\
\text { Severity } \\
\text { L-C }\end{array}$ & $\begin{array}{c}\text { Percent } \\
\text { Extent } \\
\text { Total }\end{array}$ & $\begin{array}{c}\text { Percent } \\
\text { Severity } \\
\text { Total }\end{array}$ \\
\hline TG & -4.7 & -5.0 & -6.1 & -10.3 & -6.9 & -8.2 & -5.2 & -3.2 & -22.9 & -21.8 \\
\hline HPG & +1.5 & +8.0 & +5.2 & +18.1 & +15.3 & +12.7 & +17.7 & +13.2 & +39.7 & +52.0 \\
\hline p Value & $<0.20$ & $<0.005$ & $<0.005$ & $<0.001$ & $<0.001$ & $<0.001$ & $<0.001$ & $<0.005$ & $<0.001$ & $<0.001$ \\
\hline
\end{tabular}

$\mathrm{TG}=$ treatment group, $\mathrm{HPG}=$ high-protein group, $\mathrm{LAD}=$ left anterior descending, $\mathrm{RCA}=$ right coronary artery, $\mathrm{LCx}=$ left circumflex, $\mathrm{L}-\mathrm{C}=$ left anterior descending-left circumflex, $\mathrm{p}$ value $=$ level of statistical significance between groups.

of all study participants independent of diet treatment, and their semi-quantitative measures of MPI to determine the relationship between changes in surrogate markers of heart disease (cholesterol-HDL, LDL, VLDL, triglycerides, insulin resistance-TG/HDL, fibrinogen, homocysteine, lipoprotein(a), CRP and interleukin-6-IL) and actual measured changes in CAD.

In the first part of the study [28], 28-people were placed on a moderate fat (MF) diet, 16-people followed a Phase I Fleming Diet (Phase I)-explained in further detail elsewhere [23,29], 38-individuals were placed on Phase II Fleming Diet (Phase II), and 38-participants were placed on a high fat (HF) LowCarbKetogenic Diet (LCKD), as shown in Table 3.
As expected serum lipid levels and markers of inflammation increased as the fat content of the diet increased; however, the LCKD (HF) diet showed the most increase and was the only dietary regimen associated with an increase in fibrinogen levels. The results of the changes in these blood tests are shown in Table 4, Figure 4.

The importance of these measured changes in blood levels of lipids and markers of inflammation cannot be overstated, as they are consistent with what others have reported in the literature [30,31]; however, the question remains - as raised $[24,25,27]$ previously-how reliable are changes in these blood tests as they relate to measured changes in CAD? For this, we turned to the second part of the study [9]. 
Table 3: Four fundamentally different diets investigated for their impact on serum blood markers of hyperlipidemia and inflammation [1].

\begin{tabular}{|lcccc|}
\hline Diet & $\begin{array}{c}\text { Total CALORIES } \\
\text { (KCAL/DAY) }\end{array}$ & $\begin{array}{c}\text { FAT } \\
(\mathrm{G} / \% \text { KCAL/TOTAL } \\
\left.\text { KCAL/DAY }^{-1}\right)\end{array}$ & $\begin{array}{c}\text { CARBOHYDRATES } \\
(\mathrm{G} / \% \text { KCAL/TOTAL } \\
\left.\text { KCAL/DAY }^{-1}\right)\end{array}$ & $\begin{array}{c}\text { PrOTEIN } \\
(\mathrm{G} / \% \text { KCAL/TOTAL } \\
\text { KCAL/DAY }^{-1} \text { ) }\end{array}$ \\
\hline Typical American diet & 2200 & $85 / 35 \% / 770$ & $275 / 50 \% / 1100$ & $82 / 15 \% / 330$ \\
High-fat & $1400-1500$ & $97 / 55 \%-65 \% / 870$ & $36 / 10 \% / 145$ & $100 / 25 \%-30 \% / 400$ \\
Moderate-fat & $2000-2200$ & $58 / 20 \%-30 \% / 525$ & $315 / 60 \% / 1260$ & $79 / 15 \% / 315$ \\
$\begin{array}{l}\text { Moderate-fat, calorie- } \\
\text { controlled (phase II) }\end{array}$ & $1500-1600$ & $26 / 15 \% / 232$ & $271 / 70 \% / 1085$ & $58 / 15 \% / 232$ \\
Low-fat (phase I) & $1300-1400$ & $15 / 10 \% / 135$ & $253 / 75 \% / 1012$ & $51 / 15 \% / 202$ \\
\hline
\end{tabular}

Table 4: Changes in weight, lipid and inflammatory blood tests, from baseline following four prescribed dietary regimens at 4-, 8- and 12-months.

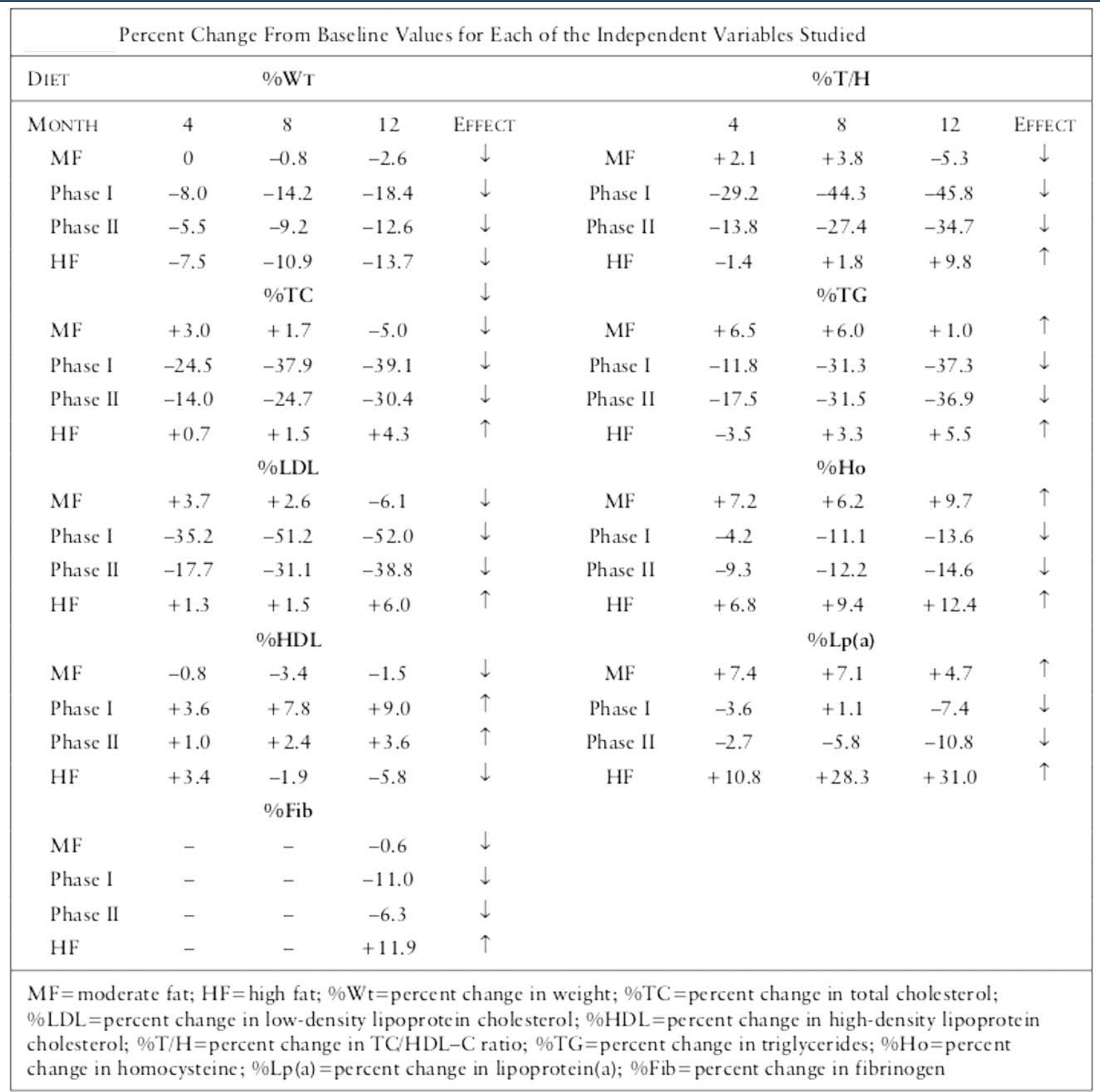

One of the very fundamentals aspects involved in diagnosing and treating patients is the use of applicable tests to determine (A) if a problem is present, and (B) has treatment helped the patient. Reliance upon these tests is determined by outcomes based medicine [32-34] and our ability to depend upon our test results to provide meaningful/useful data to guide our treatment.

Citation: Fleming RM, Fleming MR (2020) The Impact of Low Carb-KETO Diets on CAD-Why more Research is needed. J Cardiovasc Med Cardiol 7(2): 110-121. DOI: https://dx.doi.org/10.17352/2455-2976.000124 

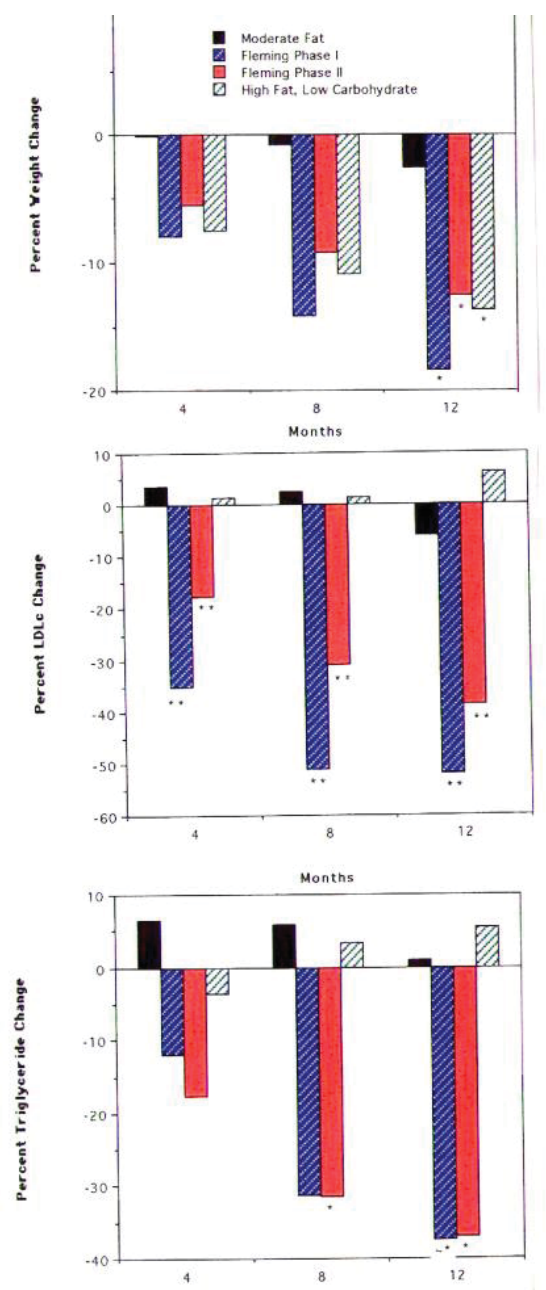

Months
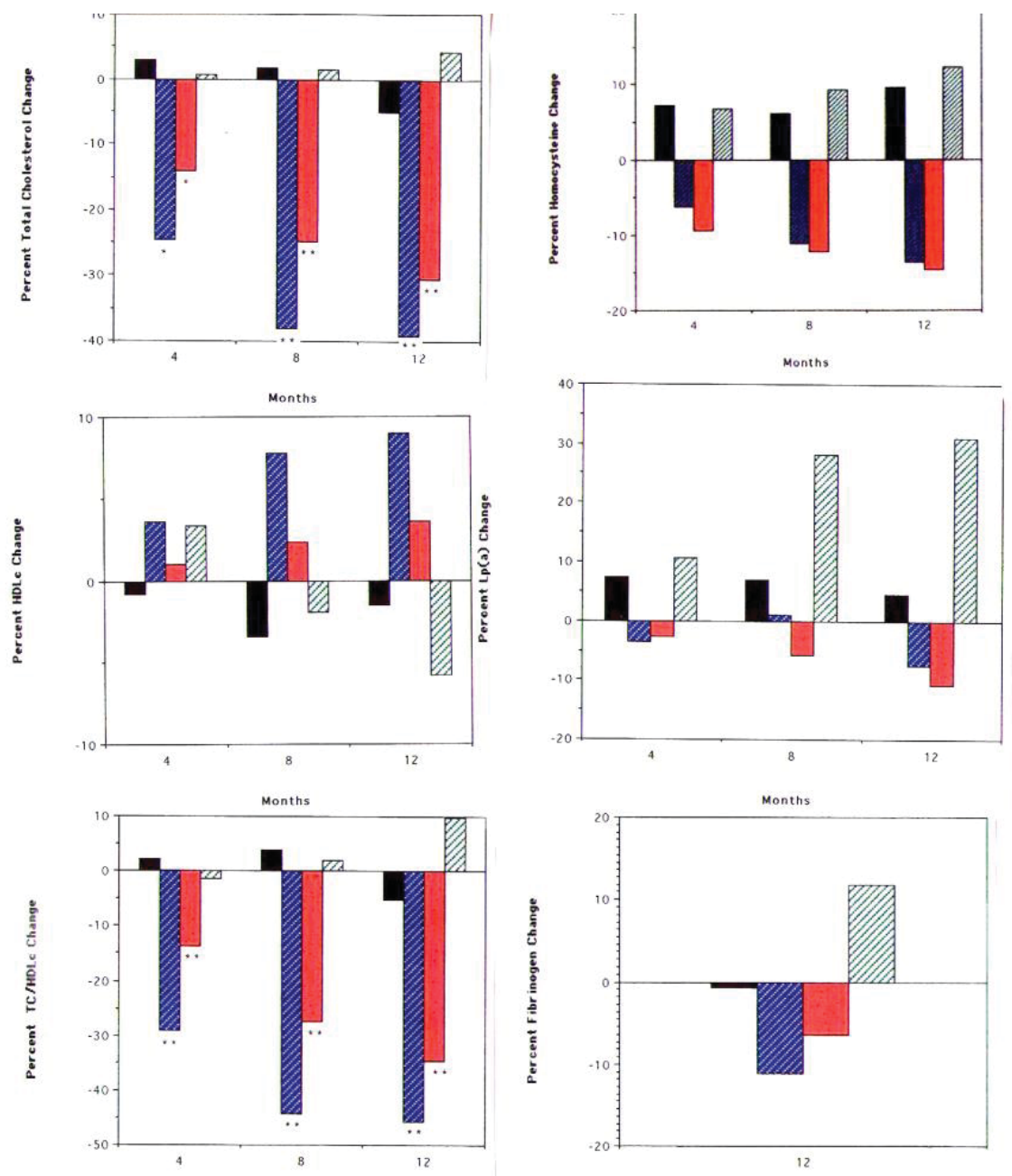

Figure 4: The bar graphs show the percent change from baseline for weight and each of 8-meausred blood tests for lipids and inflammation at 4-, 8- and 12-months on each of four dietary regimens.

While it is clear what many of the factors responsible for the production of inflammatory CAD plaques and their subsequent impairment in regional coronary blood flow producing angina are [1], the questions remained: What is the relationship between the measured lipid and inflammatory markers and CAD itself? [1], and What is the relationship between changes in these blood tests and changes in measured CAD itself?

By combining the results of all the study participants together, with their resulting increased and decreased changes in lipid and inflammatory markers from baseline, the changes in these blood tests were compared with the changes in measured coronary blood flow [9].

When baseline values and changes in coronary blood flow following a year of dietary treatment was compared with baseline values and 1-year changes in Total Cholesterol (TC), Low-Density Lipoprotein cholesterol (LDL), Very Low-Density Lipoprotein Cholesterol (VLDL), High-Density Lipoprotein cholesterol (HDL), Triglycerides (TG), TG/HDL (Insulin Resistance), lipoprotein(a)-(Lp), Homocysteine (Hcy), Fibrinogen (Fib), C-Reactive Protein (CRP) and literleukin-6 (IL), we discovered the following extremely important clinical information.
First, when the baseline values in coronary blood flow were measured using semi-quantitative ischemic index (II) from the extent and severity of blood flow reduction as described previously [27] and as shown in Figure 5, were compared with the measured baseline blood tests results, there was no demonstrable relationship $\left(\mathrm{P}=0.38, \mathrm{R}^{2}=0.0078\right)$ between the blood tests and the measured coronary blood flow as shown in Table 5 . Hence, if the patient has not been seen before, merely drawing these blood tests will not tell you if the patient has or doesn't have CAD. This is the fundamental difference [3234] between understanding the important difference between blood levels of lipids and inflammatory markers and the actual tissue level of inflammation (CAD) itself.

Secondly, having found that these 11-blood tests were not diagnostic of the extent of actual coronary artery blood flow status, we then asked whether changes in these risk factors as measured in the blood were associated with changes in CAD. Table 6 shows the results of the relationship between these 11-blood tests and changes in coronary blood flow. While suggestive of a possible benefit - it was not conclusive - so we conducted further varimax factor analysis and discovered that changes in 5 of the 11-blood tests moderately correlated with 
changes in Coronary Artery blood flow (CAD), when combined together.

Of these Triglycerides (fat), TC, Lp(a), IL-6, and HDLin decreasing order of magnitude-provided some predictive value as shown in Table 7 . Fibrinogen showed some potential predictive value and was therefore included in the final regression analysis as shown in Figure 6.

Combined together these 6-blood tests provide a regression coefficient of 0.47 to 0.70 , with an $\mathrm{R}^{2}$ of 0.36 -consistent with a moderate relationship between changes in these 6-blood tests and changes in coronary blood flow, with no relationship between initial measurements of all 11-blood tests and initial measurement of coronary blood flow. Absent the initial measure of coronary blood flow, the changes in these 6-blood tests provide little useful clinical information-reminding us to appreciate that correlation does not mean cause and effect [35].

Having repeatedly demonstrated the statistically significant beneficial effect of reducing caloric intake, refined processed foods and fat content in the diet and the adverse - although not remarkably statistically significant changes - effects of LCKD on several blood tests, several of which are not correlated with changes in coronary blood flow, we set out to conduct the third and recently published study looking not only at changes

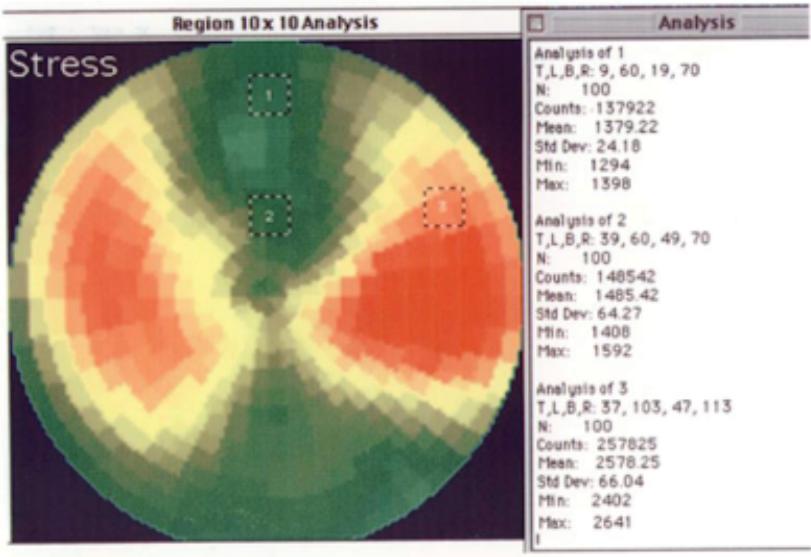

- Region 1: $Q=137922 / 100 / 28$ equals 49.26

- Region 2: $Q=148542 / 100 / 28$ equals 53.05

- Region 3: $\mathrm{Q}=257825 / 100 / 28$ equals 92.08

Figure 5a: Semi-quantification of myocardial blood flow using myocardial perfusion imaging (MPI), to provide an Ischemic Index.

(a). Region-of-interest quantification of isotope.

This bull's-eye display of isotope flow (Q) shows how regions of interest (ROIs) are quantified. Three ROIs are shown, each of which represent $10 \times 10$ pixels for a total pixel area of $100(\mathrm{~N}=100)$. To the right of the color image, the actual radioactive counts are shown along with the mean \pm standard deviation of these counts along with the minimal and maximal counts throughout the ROI. The isotope flow is further standardized by measuring the radioactive counts $(C) /$ number of pixels per $\mathrm{ROI}(\mathrm{P}) /$ the number of millicuries (M) of isotope administered (CPM). As shown, the flow $(Q)$ in region 1 is less (49.26) than region 2 (53.05), however, qualitatively both regions are displayed as green on the color-coded image. The third region is displayed in red and quantitatively shown to have the greatest amount of isotope (blood) flow with a value of $92.08 \mathrm{CPM}$.

- Region 1: Q=137922/100/28 equals 49.26

- Region 2: Q=148542/100/28 equals 53.05

- Region 3: Q=257825/100/28 equals 92.08

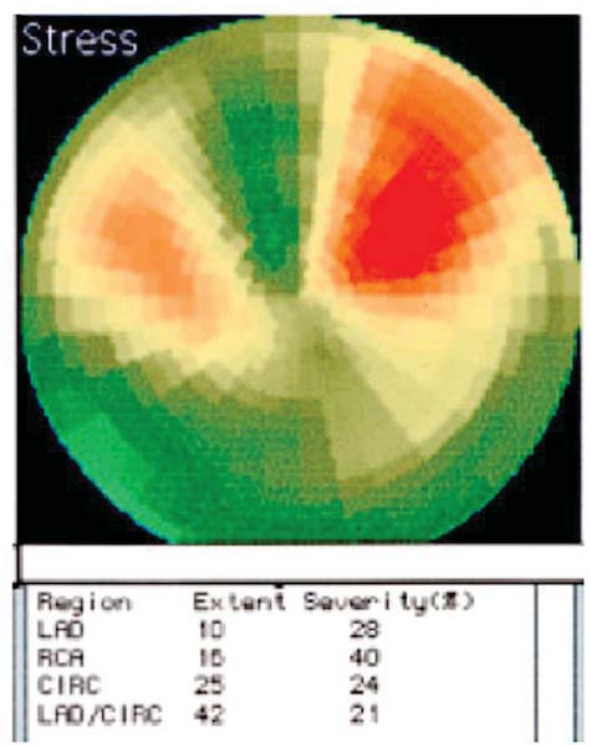

Figure 5b: Resulting Ischemic Index (II) obtained from myocardial perfusion
imaging.
Qualitative determination of regional perfusion differences determined by color
scale as shown here is a frequent method of MPI interpretation. Nuclear computers
assign colors based upon quantitative information obtained by the camera. This
same information can be seen by the investigator when asked for as shown in
the figure. This example shows four regions perfused by the epicardial arteries
including the left anterior descending (LAD) artery, the right coronary (RCA) artery,
the left circumflex (LCx or CIRC) artery and the region supplied by both the LAD
and CIRC arteries which is sometimes referred to as the watershed zone or region.
Each region accounts for a portion of the entire myocardium. All four regions added
together account for $100 \%$ of total myocardial blood flow. When each arterial
region is taken into account it represents a certain extent of the entire myocardium.
Within that region, a reduction in blood flow can be quantified to determine both the
amount (extent) of the region involved and the severity (reduction in isotope flow)
of disease in that region, yielding an ischemic index (ii) for the given artery. When
all of these regions of ischemia (ii) are added together, a total Ischemic Index (II)
for the heart is determined.

in these frequently tested for blood tests but also changes in enhanced semi-quantitative measurements of coronary blood flow.

\section{The third of the LCKD studies}

In an effort to enhance the amount of information obtained from this study, and to increase the role of study participants in their selection of foods-reducing dependence upon the study coordinators-self-efficacy behavioral counseling occurred every 6-weeks during sessions where fasting blood work was obtained. Initial coronary blood flow (MPI) imaging and semi-quantification using the methods already discussed were obtained at the beginning and end of the 12-month intervention period. An additional evaluation was performed approximately 4-months following study completion to measure any changes in dietary habits and resulting changes in blood work. The full details of this study flow are shown in Figure 7 [36].

Of the 120-final study participants, subjects were randomly assigned to one of six treatment groups based upon the roll of a die. Once a group was full it was closed to further participants. The three fundamental dietary groups consisted of a vegan group, a low to moderate fat $(15-20 \%$ of caloric intake)

Citation: Fleming RM, Fleming MR (2020) The Impact of Low Carb-KETO Diets on CAD-Why more Research is needed. J Cardiovasc Med Cardiol 7(2): 110-121. DOI https://dx.doi.org/10.17352/2455-2976.000124 
and a LCKD group. While the LCKD group had the option of consuming up to 100 grams of carbohydrate per day - on the basis of the urinary ketone results these participants more than sufficiently reduced their carbohydrate intake to qualify for LCKD.

In addition to dietary counseling and measurement of compliance with dietary counseling through the use of urine ketone testing and measurement of respiratory quotients (RO), half of each dietary group was provided with a B-6, B-12, folate supplement, to assure adequate intake independent of any potential dietary limitations - which had been suggested by previous studies $[27,28]$.

While there were no statistically significant differences between groups upon entry into the study, there were clearly

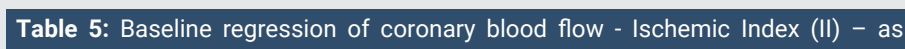
estimated by blood chemistry risk factors.

\begin{tabular}{lrcrr}
\hline Coefficients & Estimate & Standard Error & $t$ Value & $\operatorname{Pr}(>|t|)$ \\
\hline Intercept $)$ & $-1.252 \mathrm{e}-01$ & $1.952 \mathrm{e}-01$ & -0.641 & 0.5228 \\
TC & $-2.337 \mathrm{e}-03$ & $5.781 \mathrm{e}-03$ & -0.404 & 0.6868 \\
LDL & $2.746 \mathrm{e}-03$ & $5.821 \mathrm{e}-03$ & 0.472 & 0.6380 \\
Low HDL & $3.928 \mathrm{e}-03$ & $7.570 \mathrm{e}-03$ & 0.519 & 0.6049 \\
TC/HDL & $6.978 \mathrm{e}-04$ & $2.928 \mathrm{e}-02$ & 0.024 & 0.9810 \\
TG & $4.751 \mathrm{e}-04$ & $1.370 \mathrm{e}-03$ & 0.347 & 0.7294 \\
TG/HDL & $1.374 \mathrm{e}-04$ & $4.036 \mathrm{e}-02$ & 0.003 & 0.9973 \\
CRP & $3.062 \mathrm{e}-04$ & $2.725 \mathrm{e}-03$ & 0.112 & 0.9107 \\
IL & $-8.593 \mathrm{e}-04$ & $1.466 \mathrm{e}-03$ & -0.586 & 0.5591 \\
Hcy & $-3.011 \mathrm{e}-04$ & $6.488 \mathrm{e}-04$ & -0.464 & 0.6436 \\
Fib & $1.749 \mathrm{e}-04$ & $7.745 \mathrm{e}-05$ & 2.259 & 0.0259 \\
Lp & $4.030 \mathrm{e}-04$ & $4.458 \mathrm{e}-04$ & 0.904 & 0.3680
\end{tabular}

Note: TC, total cholesterol; LDL, low-density lipoprotein; HDL, high-density lipoprotein; TG, triglycerides; CRP, C-reactive protein; IL, interleukin; Hcy, homocysteine; Fib, fibrinogen; Lp, lipoprotein.

-Residuals: -0.1057 (Min), -0.0352 (1Q), -0.0057 (Median), 0.0267 (3Q), 0.1529 (Max).

${ }^{b}$ No statistically significant (Bonferroni) coefficients; residual standard error: 0.05342 on 108 degrees of freedom; multiple $R^{2}$ : 0.09955 , adjusted $R^{2}: 0.007837$; F-statistic: 1.085 on 11 and 108 DF, $P$ value: . 3798.

\begin{tabular}{|c|c|c|}
\hline Coefficients & Linear & Robust \\
\hline (Intercept) & 0.0 & -0.0671 \\
\hline $\mathrm{TC}$ & -3.0460 & -2.5141 \\
\hline LDL & 2.7440 & 2.1774 \\
\hline Low HDL & 0.1684 & 0.0697 \\
\hline $\mathrm{TC} / \mathrm{HDL}$ & 0.2819 & 0.2947 \\
\hline TG & 1.4230 & 1.2793 \\
\hline TG/HDL & -0.6348 & -0.7153 \\
\hline CRP & -0.0134 & -0.0331 \\
\hline IL & 0.0502 & 0.0301 \\
\hline Hey & 0.0579 & 0.0544 \\
\hline $\mathrm{Fib}$ & 0.1746 & 0.1098 \\
\hline Lp & 0.0542 & 0.0462 \\
\hline Residual standard error & 0.8327 & 0.5533 \\
\hline
\end{tabular}

Note: TC, total cholesterol; LDL, low-density lipoprotein; HDL, high-density lipoprotein; TG, triglycerides; CRP, C-reactive protein; IL, interleukin; Hcy, homocysteine; Fib, fibrinogen; Lp, lipoprotein.

Residuals-Linear: -2.2006 (Min), -0.3913 (1Q), -0.0399 (Median), 0.3430 (3Q), 3.0821 (Max); Robust: -2.2605 (Min), -0.3488 (IQ), 0.0125 (Median), 0.3325 (3Q), 3.3593 (Max).

${ }^{b}$ Multiple $R^{2}$ (Linear): 0.3706, adjusted $R^{2}$ : 0.3065 ; F-statistic: 5.782 on 11 and 108 DF; $P$ value: $2.736 \mathrm{e}-07$.
Table 7: Changes in 5-blood tests are predictive of changes in coronary blood flow.

\begin{tabular}{lccc}
\hline Coefficients & Estimate & $t$ Value & $\operatorname{Pr}(>|t|)$ \\
\hline Intercept & 0 & 0 & $1.000^{\mathrm{b}}$ \\
Factorl cholesterol & .276 & 3.648 & $0.000^{\mathrm{c}}$ \\
Factor2 fat & .329 & 4.315 & $0.000^{\mathrm{c}}$ \\
Factor3 low high- & .133 & 1.747 & $0.083^{\mathrm{b}}$ \\
$\quad$ density lipoprotein & & & \\
Factor4 interleukin-6 & .173 & 2.236 & $0.027^{\mathrm{d}}$ \\
Factor5 lipoprotein-a & .220 & 2.897 & $0.005^{\mathrm{e}}$ \\
Fibrinogen measure & .180 & 2.299 & $0.023^{\mathrm{d}}$
\end{tabular}

"Residuals: -2.084051 (Min), -0.412194 (1Q), -0.001096 (Median), 0.400191 (3Q), 3.106253 (Max)

Significance codes: ${ }^{b} 0.1,{ }^{\circ} 0.001,{ }^{\mathrm{d}} 0.05,{ }^{\mathrm{c}} 0.01$.

fResidual standard error: 0.83 on 113 degrees of freedom; multiple $R^{2}$ : 0.36 , adjusted $R^{2}: 0.32$; F-statistic: 10.46 on 6 and 113 DF; $P$ value: $3.333 \mathrm{e}-09$.

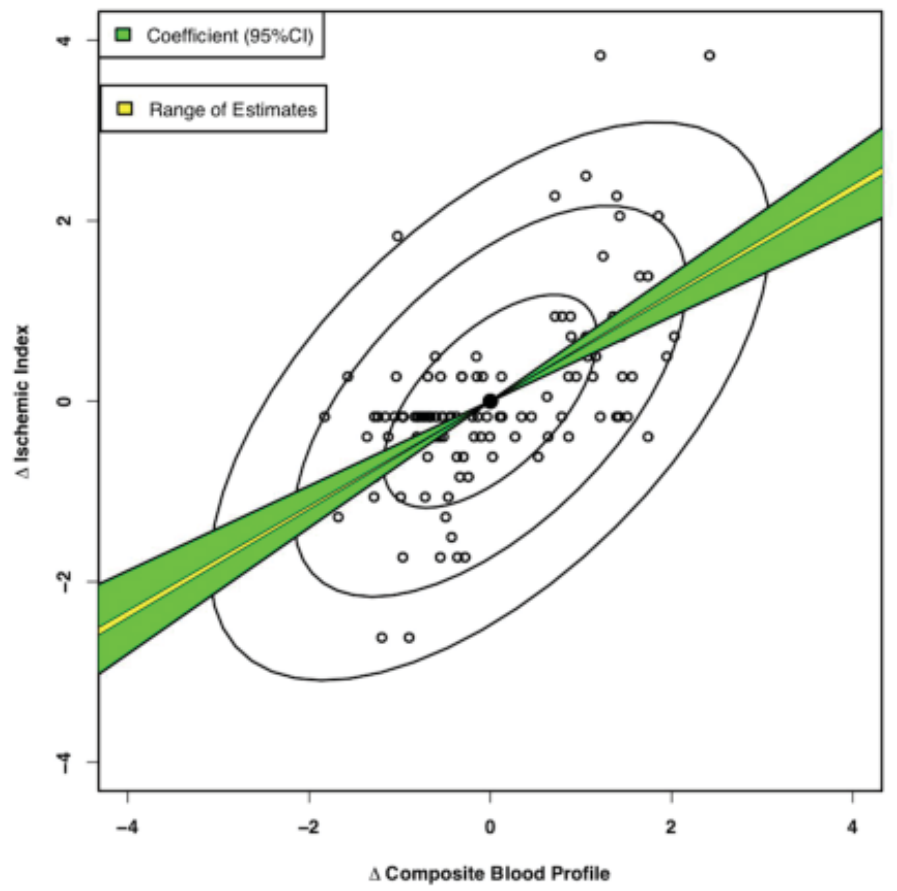

Figure 6: Blood flow changes versus Blood chemistry changes.

Standardized regression of coronary blood flow (nuclear imaged ischemic index) on composite blood profile (cholesterol, fat-triglycerides, HDL, IL-6, Lp-a, and Fib). The $X$-axis displays the composite blood profile including TC, fat, low HDL, IL-6, Lp, and Fib. The Y-axis displays changes in ischemia as measured by nuclear imaging. The standard regression analysis shows both the range of estimates (yellow) and the $95 \%$ confidence intervals (green). HDL, high-density lipoprotein; IL-6, interleukin-6; Lp-a, lipoprotein-a; Fib, fibrinogen; Tc, total cholesterol.

statistically significant differences between the groups by the end of the study. Those following LCKD regimens demonstrated both worsening of their blood tests results and a reduction in their coronary blood flow. The best outcomes were seen by those following the low to moderate fat intake, with the vegan group having results similar to the low to moderate fat group.

Table 8, Figure 8, shows the change for each group following 1-year of treatment for each of the 16-variables including BMI, Respiratory Quotient, coronary blood flow, total cholesterol, very-low density lipoprotein, low density lipoprotein, high density lipoprotein, TC/HDL ratio, triglycerides, insulin resistance as assessed using TG/HDL ratio, Interleukin-6, 


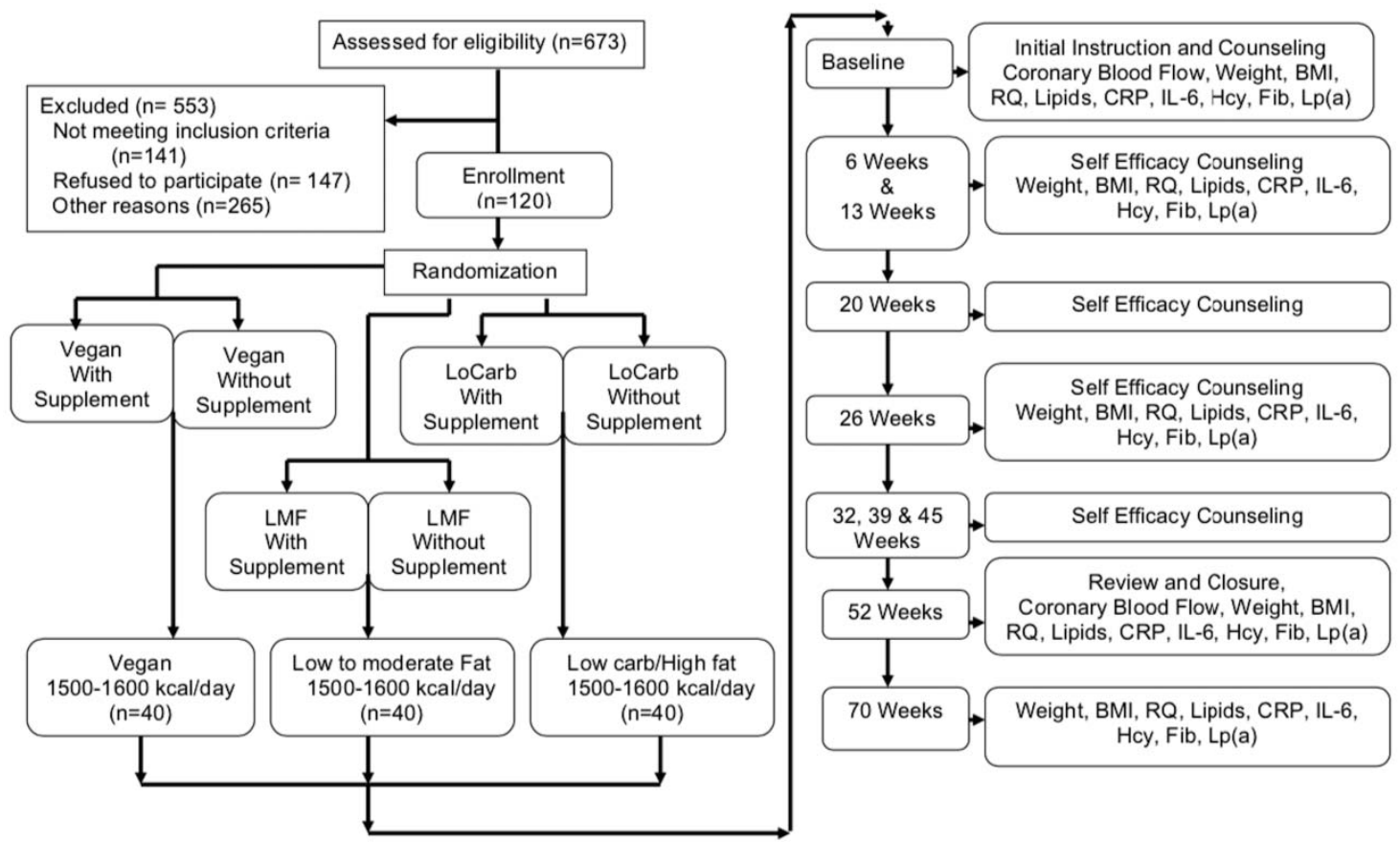

Figure 7: Study participant recruitment and testing sequence.

Patent recruitment and sequence of counseling and testing from entry through the 4-month follow up after completion of the 12-month study.
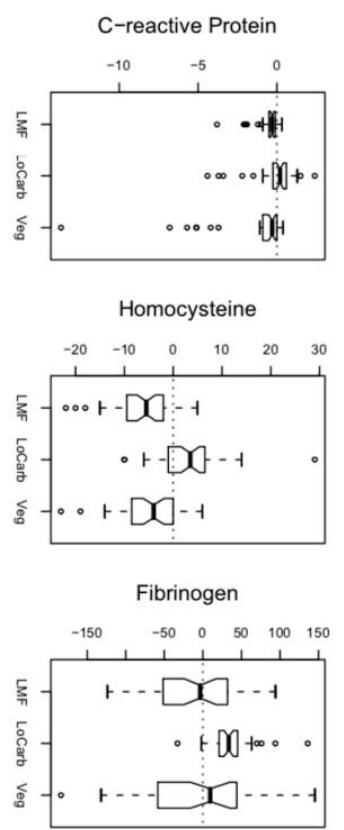

Lipoprotein(a)

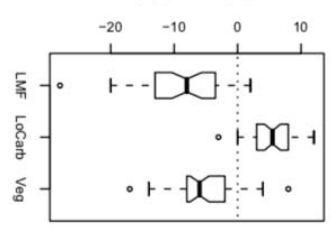

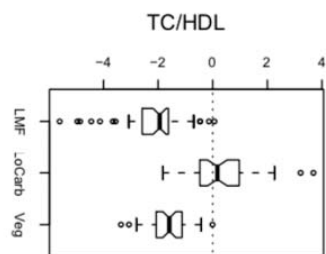

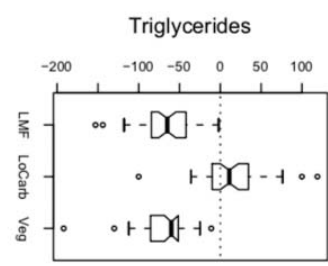

Insulin Resistance(TG/HDL)

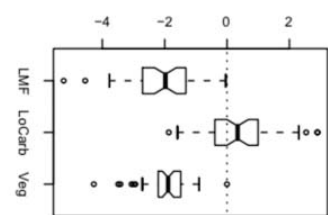

Interleukin-6

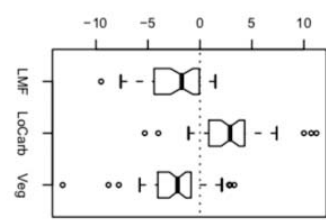

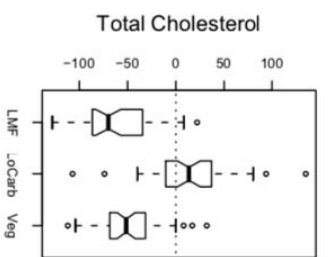

Very Low Density Lipoprotein

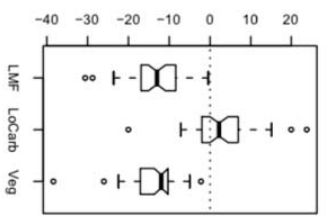

Low Density Lipoprotein

$\begin{array}{ccccc}-100 & -50 & 0 & 50 & 100\end{array}$

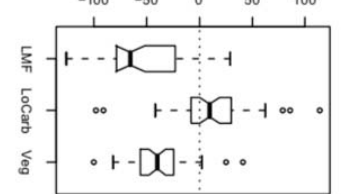

High Density Lipoprotein

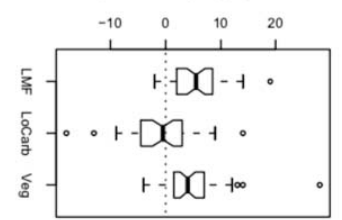

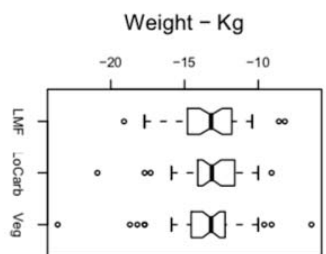

Body Mass Index

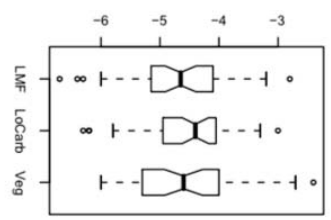

Respiratory Quotient

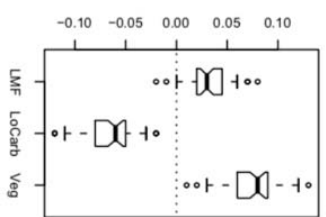

Coronary Blood Flow

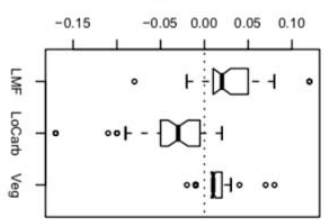

Figure 8: Changes in each of the measured outcomes for each dietary group over 1-year.

Notched boxplots of quantile distributions of 1-year changes in each cardiovascular risk factor index under each target diet. Boxes include the interquartile range; whiskers extend 1.5 times the interquartile range; all outliers are shown. Medians differ significantly $(p<0.05)$ for non-overlapping notches.

Citation: Fleming RM, Fleming MR (2020) The Impact of Low Carb-KETO Diets on CAD-Why more Research is needed. J Cardiovasc Med Cardiol 7(2): 110-121. DOI: https://dx.doi.org/10.17352/2455-2976.000124 
C-reactive protein, homocysteine, fibrinogen and finally lipoprotein(a). Table 8, also shows the results for each group compared with the other two groups.

Finally, it should be noted that eating is a behavior associated with species survival, which would suggest considerable genetic material being devoted to this survival mechanism. In an effort to determine what impact the dietary counseling would have, after the participants had been instructed in self-efficacy counseling (Bandura conditioning - [37]), participants were asked to return for measurement of respiratory quotients to determine any potential changes in dietary patterns, in addition to weight and height measurements for BMI calculation. The results of which demonstrated an increase in carbohydrate consumption among the LCKD group and a decrease in carbohydrate consumption among the Vegan participants. BMI remained stable or improved, with the exception of the LCKD group.

\section{Table 7: Changes in 5-blood tests are predictive of changes in coronary blood flow.}

\begin{tabular}{lccc}
\hline Coefficients & Estimate & $t$ Value & $\operatorname{Pr}(>|t|)$ \\
\hline Intercept & 0 & 0 & $1.000^{\mathrm{b}}$ \\
Factor1 cholesterol & .276 & 3.648 & $0.000^{\mathrm{c}}$ \\
Factor2 fat & .329 & 4.315 & $0.000^{\mathrm{c}}$ \\
Factor3 low high- & .133 & 1.747 & $0.083^{\mathrm{b}}$ \\
$\quad$ density lipoprotein & & & \\
Factor4 interleukin-6 & .173 & 2.236 & $0.027^{\mathrm{d}}$ \\
Factor5 lipoprotein-a & .220 & 2.897 & $0.005^{\mathrm{e}}$ \\
Fibrinogen measure & .180 & 2.299 & $0.023^{\mathrm{d}}$ \\
\hline
\end{tabular}

"Residuals: -2.084051 (Min), -0.412194 (1Q), -0.001096 (Median), 0.400191 (3Q), 3.106253 (Max)

Significance codes: ${ }^{\mathrm{b}} 0.1,{ }^{\mathrm{c}} 0.001,{ }^{\mathrm{d}} 0.05,{ }^{\mathrm{c}} 0.01$.

'Residual standard error: 0.83 on 113 degrees of freedom; multiple $R^{2}$ : 0.36 , adjusted $\mathrm{R}^{2}$ : 0.32 ; F-statistic: 10.46 on 6 and 113 DF; $P$ value: $3.333 \mathrm{e}-09$.

\section{Discussion and the need for further quantification}

Following almost three-quarters of a century of debate, it is now clearly understood that $\mathrm{CAD}$ is an inflammatory process [1] resulting from more than cholesterol. A process associated with ever increasing tissue levels of inflammatory materials [1], which ultimately result in the deposition of an inflammatory plaque that impairs the ability of coronary arteries to dilate to increase coronary blood flow upon demand. Until recently $[11,38]$, our ability to measure coronary blood flow has been limited to semi-quantitative measurements.

A review of the three studies done to date - looking at the blood levels of lipids, inflammatory markers and semiquantitative coronary blood flow in individuals on Vegan, LMF and LCKD - reveals no relationship between initial measurements of these blood tests and coronary blood flow itself, and only a moderate relationship between changes in a composite of 6-combined blood tests and actual changes in coronary blood flow.

While changes in lipids and inflammatory blood tests have been repeatedly shown to increase following treatment with a LCKD, the failure to demonstrate a statistically significant correlation between outcomes on blood tests (blood levels of inflammation) and consequential changes in coronary blood flow (tissue levels of inflammation) makes it impossible to predict with certainty what these and other diets are doing to the coronary blood flow proper.

If we as physicians are going to talk to our patients, or publish papers in medical journals, or discuss findings with the media - so the media can write second hand stories, which someone else will write third hand stories about - then

Table 8: Changes in each of the measured outcomes within groups following 1-year of dietary intervention and comparisons between groups.

\begin{tabular}{|c|c|c|c|c|c|c|}
\hline \multirow{2}{*}{\multicolumn{4}{|c|}{$\begin{array}{ll}95 \% \mathrm{Cl} \text { of Changes within Diet Groups and between Diet Groups in } \\
\\
\text { Index (Risk factor) }\end{array}$}} & \multicolumn{3}{|c|}{ Between diet groups } \\
\hline & & & & Locarb-LMF & Veg-LMF & LoCarb-Veg \\
\hline Body Mass Index $\left(\mathrm{kg} / \mathrm{m}^{2}\right)$ & -4.93 to -4.39 & -4.78 to -4.24 & -4.91 to -4.38 & -0.24 to +0.53 & -0.32 to +0.45 & -0.30 to +0.47 \\
\hline Respiratory Quotient & +0.02 to +0.04 & -0.07 to -0.06 & +0.07 to +0.08 & -0.11 to -0.09 & +0.03 to +0.05 & -0.08 to -0.05 \\
\hline Coronary Blood Flow & +0.04 to +0.02 & -0.02 to -0.05 & +0.02 to +0.00 & -0.05 to -0.08 & +0.00 to -0.03 & -0.03 to -0.06 \\
\hline Total Cholesterol (mg/dl) & -72.3 to -48.1 & -0.43 to +23.8 & -60.2 to -35.9 & +54.8 to +89.0 & -5.00 to +29.3 & +42.6 to +76.9 \\
\hline VLDL $(\mathrm{mg} / \mathrm{dl})$ & -15.8 to -11.4 & +0.82 to +5.21 & -16.0 to -11.6 & +13.5 to +19.7 & -3.32 to +2.30 & +13.7 to +19.9 \\
\hline $\mathrm{LDL}(\mathrm{mg} / \mathrm{dl})$ & -63.9 to -40.8 & -2.15 to +21.0 & -50.7 to -27.6 & +45.4 to +78.2 & -3.14 to +29.6 & +32.2 to +64.9 \\
\hline $\mathrm{HDL}(\mathrm{mg} / \mathrm{dl})$ & +4.32 to +7.68 & -2.56 to +0.81 & +3.27 to +6.63 & -9.25 to -4.50 & -3.43 to +1.33 & -8.20 to -3.45 \\
\hline $\mathrm{TC} / \mathrm{HDL}$ & -2.56 to -1.86 & -0.01 to +0.69 & -1.99 to -1.29 & +2.06 to +3.04 & +0.08 to +1.06 & +1.49 to +2.47 \\
\hline Triglycerides (mg/dl) & -79.0 to -57.0 & +4.11 to +26.1 & -80.1 to -58.1 & +67.6 to +98.6 & -16.6 to +14.5 & +68.6 to +99.7 \\
\hline Insulin Resistance (TG/HDL ) & -2.43 to -1.78 & +0.08 to +0.72 & -2.26 to -1.62 & +2.04 to +2.96 & -0.30 to +0.62 & +1.88 to +2.80 \\
\hline Interleukin-6 (pg/ml) & -3.40 to -1.44 & +1.88 to +3.85 & -3.45 to -1.48 & +3.89 to +6.67 & -1.44 to +1.35 & +3.94 to +6.72 \\
\hline C-reactive Protein (mg/dl) & -1.08 to +0.06 & -0.64 to +0.50 & -1.86 to -0.72 & -0.37 to +1.25 & -1.59 to +0.03 & +0.41 to +2.03 \\
\hline Homocysteine (mmol/L) & -8.36 to -4.30 & +1.13 to +5.36 & -6.50 to -2.46 & +6.78 to +12.5 & -1.02 to +4.72 & +4.93 to +10.7 \\
\hline Fibrinogen (mg/dl) & -24.0 to +8.91 & +18.3 to +51.2 & -20.6 to +12.3 & +19.1 to +65.6 & -19.9 to +26.7 & +15.7 to +62.2 \\
\hline Lipoprotein (a) (mg/dl) & -10.7 to -7.36 & +3.76 to +7.09 & -6.97 to -3.63 & +12.1 to +16.8 & +1.37 to +6.08 & +8.37 to +13.1 \\
\hline
\end{tabular}



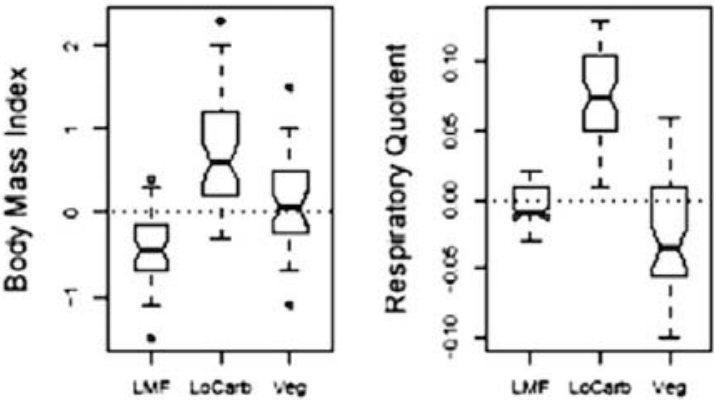

Figure 9: Changes in dietary eating habits as measured by changes in respiratory quotients (RQ) revealed no change 4-months post dietary counseling for the group following the low to moderate fat (LMF) dietary regimen, which continued to show weight loss with continued reduction in BMI. The vegan group showed further reduction in carbohydrate consumption as revealed by the continued reduction in $\mathrm{RQ}$ with little change in weight, while the LCKD (LoCarb) group showed weight gain - increasing BMI - and increased consumption of carbohydrates revealed by the increased RQ.

we need to conduct further studies on the impact of these diets, quantitatively measuring the effect these diets have on coronary blood flow. There is no substitute for measuring the effect of a drug or diet upon coronary blood flow other than the quantification of the change in coronary blood flow itself.

\section{Conclusion}

While the medical and lay literature would suggest considerable information has been obtained as to the effect of LowCarb-Ketogenic diets - the opposite is true. There are only three published studies, which have measured the actual impact these diets have on the coronary arteries (CAD). These studies have admittedly used the semi-quantitative methods available at the time of their investigation.

Before people are told that LowCarb-Ketogenic diets are safe, harmful, or have no impact on heart disease - independent of their effect on weight change and blood test results - given what we know about the semi-quantitative measured changes associated with these diets, we need to first objectively measure the true effect these diets have on the arteries of the heart with FMTVDM. Then and only then will we be able to intelligently, objectively, advise patients - and the media - about these diets and their consequential impact on coronary artery disease; the number one cause of death in men and women.

Of great concern are the recent comments made by LCKD pundits claiming that patients with lower LDLc levels are at an increased risk from CoVid-19 infections and that the use of ketogenic diets are somehow protective against CoVid-19. These statements are not only scientifically unproven but also potentially quite dangerous given the measured worsening of comorbid states like CAD associated with people following these diets. Such unsubstantiated claims are concerning.

\section{Acknowledgment-potential COI}

The first author owns FMTVDM. All figures from referenced publications are reproduced with expressed consent of first author. There are no other COI to report and no funding to report.

\section{References}

1. Fleming RM (1999) Chapter 64. The Pathogenesis of Vascular Disease Textbook of Angiology John C. Chang Editor, Springer-Verlag New York NY 787-798. Link: https://bit.ly/3fxQJuW

2. Fleming RM, Fleming MR (2019) The Importance of Thinking about and Quantifying Disease like Cancer and Heart Disease on a "Health-Spectrum" Continuum. J Compr Cancer Rep 3: 1-3. Link: https://bit.ly/3ckdoc6

3. Fleming RM, Fleming MR, Chaudhuri TK (2019) FMTVDM provides first patented Quantitative Method to accurately Measure both Heart Disease and Breast Cancer on the "Health-Spectrum". J Cardiovasc Med Cardiol 6: 019020. Link: https://bit.ly/35IRTze

4. Fleming RM (2001) Coronary Artery Disease is More than Just Coronary Lumen Disease. Amer J Card 88: 599-600. Link: https://bit.ly/3bgL3T0

5. Fleming RM (2003) Angina and coronary Ischemia are the result of coronary regional Blood Flow Differences. J Amer Coll Angiol 1: 127-142. Link: https://bit.ly/3cj4sDV

6. Sheikh A (2018) Evolution of Quantification in Clinical Nuclear Medicine: A Brief Overview of Salient Uses and Upcoming Trends. J Nucl Med Radiat Ther 9: 1000375. Link: https://bit.ly/2AdrHRO

7. Fleming RM (2018) FMTVDM@(P) Provides the First True SPECT and PET Quantification and Not Virtual Guesstimation Produced by SUV and Extraction Fraction, Yielding First Accurate Theranostic Method. J Nucl Med Radiat Ther 9: 4. Link: https://bit.ly/3dmF3tg

8. Fleming RM, Fleming MR, McKusick A, Chaudhuri TK (2018) Semi-

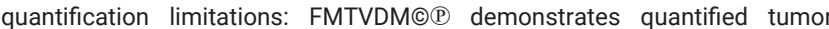
response to treatment with both regional blood flow and metabolic changes. $J$ Nucl Med 59: 1643-1644. Link: https://bit.ly/2LcuFrM

9. Fleming RM, Harrington GM (2008) What is the Relationship between Myocardial Perfusion Imaging and Coronary Artery Disease Risk Factors and Markers of Inflammation? Angiology 59: 16-25. Link: https://bit.ly/2yEvHuO

10. Fleming RM, Fleming MR, Chaudhuri TK (2019) Changes in Blood Tests Measuring Cholesterol and Inflammation Do Not Correlate with Measured Changes in Coronary Artery Disease. Biomed J Sci Tech Res 20: 15144 15146. Link: https://bit.ly/2SP9ZdX

11. The Fleming Method for Tissue and Vascular Differentiation and Metabolism (FMTVDM) using same state single or sequential quantification comparisons.

12. Johnston BC, Zeraatkar D, Han MA, Vernooij RWM, Valli C, et al. (2019) Unprocessed Red Meat and Processed Meat Consumption: Dietary Guideline Recommendations from the Nutritional Recommendations (NutriRECS) Consortium. Ann Intern Med. Link: https://bit.ly/2zpBCTI

13. Vernooij RW, Zeraatkar D, Han MA, El Dib R, Zworth M, et al. (2019) Patterns of Red and Processed Meat Consumption and Risk for Cardiometabolic and Cancer Outcomes: A Systematic Review and Meta-analysis of Cohort Studies. Ann Intern Med. Link: https://bit.ly/3ciTuOV

14. Zeraatkar D, Johnston BC, Bartoszko J, Cheung K, Bala MM, et al. (2019) Effect of Lower Versus Higher Red Meat Intake on Cardiometabolic and Cancer Outcomes: A Systematic Review of Randomized Trials. Ann Intern Med. Link: https://bit.ly/2YM2Xdv

15. Valli C, Rabassa M, Johnston BC, Kuijpers R, Prokop-Dorner A, et al. (2019) Health-Related Values and Preferences Regarding Meat Consumption: A Mixed-Methods Systematic Review. Ann Intern Med. Link: https://bit.ly/2LfQIhi

16. Zeraatkar D, Han MA, Guyatt GH, Vernooij RWM, El Dib R, et al. (2019) Red and Processed Meat Consumption and Risk for All-Cause Mortality and Cardiometabolic Outcomes: A Systematic Review and Meta-analysis of Cohort Studies. Ann Intern Med. Link: https://bit.ly/2WhcibF 
17. Han MA, Zeraatkar D, Guyatt GH (2019) Reduction of Red and Processed Meat Intake and Cancer Mortality and Incidence: A Systematic Review and Metaanalysis of Cohort Studies. Ann Intern Med. Link: https://bit.ly/35IU9G

18. Taubes G (2002) What if it's all been a big fat lie? The New York Times Magazine. Link: https://nyti.ms/2SRNBR7

19. Whittell G (2004) Dr. Atkins and the \$40bn question - was it something that he ate? Times On Line.

20. Malhotra A (2018) Why modern medicine is a major threat to public health The Guardian.

21. Should You Stop Eating Read Meat? A New Paper Has a Controversial Answer Time. 30 September 2019.

22. Fleming RM, Ketchum K, Fleming DM, Gaede R (1996) Assessing the independent effect of dietary counseling and hypolipidemic medications on serum lipids. Angiology 47: 831-840. Link: https://bit.ly/3fuvxpM

23. Fleming RM (2003) Stop Inflammation Now! Published by Putnam Books and Avery Books.

24. Fleming RM (2000) The Natural Progression of Atherosclerosis in an Untreated Patient with Hyperlipidemia: Assessment via Cardiac PET. Int J Angiol 9: 7073. Link: https://bit.ly/2WEPIIZ

25. Fleming RM (2000) The Clinical Importance of Risk Factor Modification: Looking at Both Myocardial Viability (MV) and Myocardial Perfusion Imaging (MPI). Int J Angiol 9: 65-69. Link: https://bit.ly/2zpZvdS

26. Fleming RM (2000) The Fleming Unified Theory of Vascular Disease: A Link Between Atherosclerosis, Inflammation, and Bacterially Aggravated Atherosclerosis (BAA). Angiol 51: 87-89. Link: https://bit.ly/2SPLXPK

27. Fleming RM, Boyd LB (2000) The Effect of High-Protein Diets on Coronary Blood Flow. Angiology 51: 817-826. Link: https://bit.ly/3cjRi9|

28. Fleming RM (2002) The Effect of High-, Moderate-, and Low-Fat Diets on Weight Loss and Cardiovascular Disease Risk Factors. Prev Cardiol 5: 110 118. Link: https://bit.ly/3coApuQ
29. Cardiovascular Disease: Stop Inflammation Link: https://bit.ly/2xS5Puw

30. Pogozelski W, Arpaia N, Priore S (2005) The Metabolic Effects of Lowcarbohydrate Diets and Incorporation into a Biochemistry Course. Biochem Mol Biol Educ 33: 91-100. Link: https://bit.ly/2Wg8SWv

31. Kirkpatrick CF, Bolick JP, Kris-Etherton PM, Soffer DE, Willard KE, et al. (2019) Review of current evidence and clinical recommendations on the effects of low-carbohydrate and very-low-carbohydrate (including ketogenic) diets for the management of body weight and other cardiometabolic risk factors: A scientific statement from the National Lipid Association Nutrition and Lifestyle Task Force. J Clin Lipidology 13: 689-711. Link: https://bit.ly/2WJZEkm

32. Fleming RM, Fleming MR, Chaudhuri TK (2019) Restoring the Public Trust in the Patient-Physician Relationship. Int J Nuclear Med Radioactive Subs 2 000113.

33. Fleming RM, Fleming MR, Chaudhuri TK (2019) The Need to Actually Measure What We're Talking about before We Put it All Together. Int J Nuclear Med Radioactive Subs 2: 000114

34. Fleming RM, Fleming MR, McKusick A, Chaudhuri TK (2019) Objectively measuring popular diets affect on heart disease and breast cancer. Acta Sci Pharm Sci 3: 81-92

35. Matthew R (2000) Storks Deliver Babies $(p=0.008)$. Teaching Statistics 22 36-38.

36. Fleming RM, Fleming MR, Chaudhuri TK, Harrington GM (2019) Cardiovascular Outcomes of Diet Counseling. Edel J Biomed Res Rev 1: 21-30.

37. Bandura A (1997) Self-efficacy: The exercise of control. W.H. Freeman and Company, New York. Link: https://bit.ly/3bfObQB

38. Sheikh A (2018) Evolution of Quantification in Clinical Nuclear Medicine: A Brief Overview of Salient Uses and Upcoming Trends. J Nucl Med Radiat Ther 9: 1000375. Link: https://bit.ly/2WfFgsv

\section{Discover a bigger Impact and Visibility of your article publication with} Peertechz Publications

\section{Highlights}

* Signatory publisher of ORCID

* Signatory Publisher of DORA (San Francisco Declaration on Research Assessment)

* Articles archived in worlds' renowned service providers such as Portico, CNKI, AGRIS, TDNet, Base (Bielefeld University Library), CrossRef, Scilit, J-Gate etc

* Journals indexed in ICMJE, SHERPA/ROMEO, Google Scholar etc.

* OAI-PMH (Open Archives Initiative Protocol for Metadata Harvesting)

* Dedicated Editorial Board for every journal

* Accurate and rapid peer-review process

* Increased citations of published articles through promotions

* Reduced timeline for article publication

Submit your articles and experience a new surge in publication services (https://www.peertechz.com/submission).

Peertechz journals wishes everlasting success in your every endeavours.

Copyright: (c) 2020 Fleming RM, et al. This is an open-access article distributed under the terms of the Creative Commons Attribution License, which permits unrestricted use, distribution, and reproduction in any medium, provided the original author and source are credited.

Citation: Fleming RM, Fleming MR (2020) The Impact of Low Carb-KETO Diets on CAD-Why more Research is needed. J Cardiovasc Med Cardiol 7(2): 110-121. DOI: https://dx.doi.org/10.17352/2455-2976.000124 